\title{
Autonomous power supply technology in term of natural and technogenic disasters
}

\author{
Svetlana Makasheva ${ }^{1, *}$ and Pavel Pinchukov ${ }^{1}$ \\ ${ }^{1}$ Far Eastern State Transport University, Seryshev st. 47, 680021, Khabarovsk, Russia
}

\begin{abstract}
The paper deals the problem of the energy supply after disaster and emergency. The purpose of the paper is to review the autonomous power supply technology's application to provide electricity in the aftermath of disasters for emergency relief and to remote areas having no access to the grid. Safety requirements for electric power system facilities in case of a threat of violations and/or electricity supply fault are considered. The advantages of different types of autonomous electricity sources for disaster resilience are discussed. On the example of the Sakhalin Island, Russia, a conclusion about the difficulties of using solar electricity sources during the repair and recovery works after accidents and disasters at island territories is drawn. The paper concludes by emphasizing the importance of autonomous power supply technologies in engineering education and integrating them in programs related to alternative energy and disaster \& emergency management.
\end{abstract}

\section{Introduction}

According to recent reports [the World Bank] the number of natural disasters worldwide has steadily increased during last 50 years. Natural disasters as earthquakes, cyclones, hurricanes, and flooding can happen at any time anywhere. In addition to natural disasters in recent society, there is a high risk of man-made disasters associated with both terrorist activities and human errors. The electrical power is usually the first critically important service, which lost during accident and affecting homes, hospitals, schools, food stores and other vital services. A sudden violation of power supply to important consumers can lead to the emergence of a threat to life and health of citizens, significant material losses, as well as the threat of negative impact on the environment. Because of this aspect, it is extremely important for such consumers to ensure uninterrupted power supply.

Moreover, for life-support systems for electricity consumers, it is necessary to provide power supply for the systems that ensure the continuous functioning of emergency and dispatch control in the electric power system, systems for informing centres, state authorities and local governments, as well as consumers about violations and threats of power failure. In cases of power supply black-out in term of natural and technogenic disasters, the uninterrupted power supply is also necessary for facilities that, in the event of

\footnotetext{
*Corresponding author: jap_svet@mail.ru
} 
a power failure from the electricity distribution system, must continue to function or provide a safe and accident-free termination of the technologic process [1-3].

Therefore, for these consumers and life-support systems, the autonomous power supply technologies from autonomous sources, that independent of the electricity distribution system are extremely important. Recent years have seen a significant interest growth in autonomous electric supply systems. Now, these autonomous systems are increasingly being deployed as a way to improve local power resilience, reduce reliance on fossil fuels and defer large-scale grid investments in areas that have a connection to the main electricity grid $[2,6,7]$.

However, despite the proven effectiveness of autonomous systems, their use is often limited by the consequences of destruction as a result of cataclysms. In this case, using a mobile and portable sources of electrical energy can became the problem solution. In the world practice, standalone photovoltaic (PV) systems are widely used for restoration work in the absence of centralized electric power supply [2]. However, their application can be difficult, limited or impossible due to the lack of a stable solar flow due to insufficient illumination of the location and during work in the evening and at night.

For example, the Sakhalin Region, located in the Russian Far East, is often exposed to seismic impacts, cyclones and other atmospheric incidents [8]. Sakhalin region - the country's only island region located on 87 islands, and includes the island of Sakhalin with adjoining territories islands: Houches Island, Zenkovich Island, Moneron Island, Tyuleniy Island, etc., and two Kuril islands (Big and Small) [8]. The climate of the region is mainly formed under the influence of the Asian continent and the Pacific Ocean. It is formed under the influence of monsoons of temperate latitudes, the system of sea currents and relief features and is characterized by cold dry winters and warm, humid summers.

The great length of the Sakhalin area from north to south, as well as the interaction of a number of other factors (a large meridional length, the complexity of the relief, the effect of washing the seas and currents, etc.), cause significant climate differences in its areas. At the end of summer and early autumn, there are typhoon outcrops, the passage of which is accompanied by storm winds, reaching speeds of more than 40 meters per second, and heavy rains. The specific nature of the region is high seismic and volcanic activity. This is especially characteristic of the Kuril Islands, where 36 active volcanoes are located and earthquakes quite often occur [8]. The duration of the cold period is about 140-200 days. The average temperature in January is from $-19.7{ }^{\circ} \mathrm{C}$ up to $-22.3^{\circ} \mathrm{C}$. The coldest and warmest place on Sakhalin is the central part of the Tym'- Poronayskaya lowland, where the absolute minimum of air temperature reached $-50^{\circ} \mathrm{C}$, and the absolute maximum is + $35^{\circ} \mathrm{C}$. The annual amount of precipitation is $500 \div 1000$ millimeters [8].

Great cloudiness greatly reduces the duration of sunshine. The smallest annual number of sunshine is 1722 hours (north of Sakhalin Island), the largest - 1918 hours (south of Sakhalin Island). In the Kuril Islands, the duration of sunshine is 1000 - 1600 hours per year. In such conditions, the work of solar power plants is difficult and the question arises of finding other sources of autonomous power.

The purpose of the paper is to review the autonomous power supply technology's application to provide electricity in the aftermath of disasters for emergency relief and to remote areas having no access to the grid and also in conditions of solar energy deficit.

\section{Safety requirements for electric power system facilities in case of a threat of violations and/or electricity supply fault}

In accordance with the rules of electricity supply to consumers [3], in cases of threats of violations of power supply or losing the electrical communication with the general network 
in term of natural and technogenic disasters, the life-support systems, should be able to ensure next items:

- safety of life and health of citizens, property of individuals and legal entities, state or municipal property, as well as safety for the environment;

- safe continuation of production processes of power facilities before the end of the process in full or short cycle;

- readiness of electric power industry objects to resume work after restoration of technological communication with the electrical network of general purpose;

- synchronization of registration of emergency processes, events and telemetry, safety of registered operational data and commercial metering data of electrical energy.

The Far Eastern Region of Russia including the Primorsky Territory, the Khabarovsk Territory, the Amur region and the south of Yakutia is one of two special non-price areas categories of the wholesale electricity market [4]. In contrast to the central part of Russia there are no free market electricity prices in non-price areas. Competition in the wholesale electricity and power market among generating stations is not possible because there are only two generating company at the Far East $[4,5]$. Thus, the prerequisites for autonomous power supply technologies' effective using have already been created and the advantages of their application are evident.

\section{Autonomous power supply technologies}

Microgrids, also called as Autonomous Power System (APSS), Intelligent Distributed Autonomous Power Systems (IDAPS) or Intelligent Distributed Autonomous Electric Energy System (IDEAS) as a way of providing access to electricity in off-grid locations like remote villages, mines and islands.

\subsection{Autonomous distributed energy systems types and structure}

Now, autonomous distributed energy systems are increasingly being deployed as a way to improve local power resilience, reduce reliance on fossil fuels and defer large-scale grid investments in areas that have a connection to the main electricity grid [7].

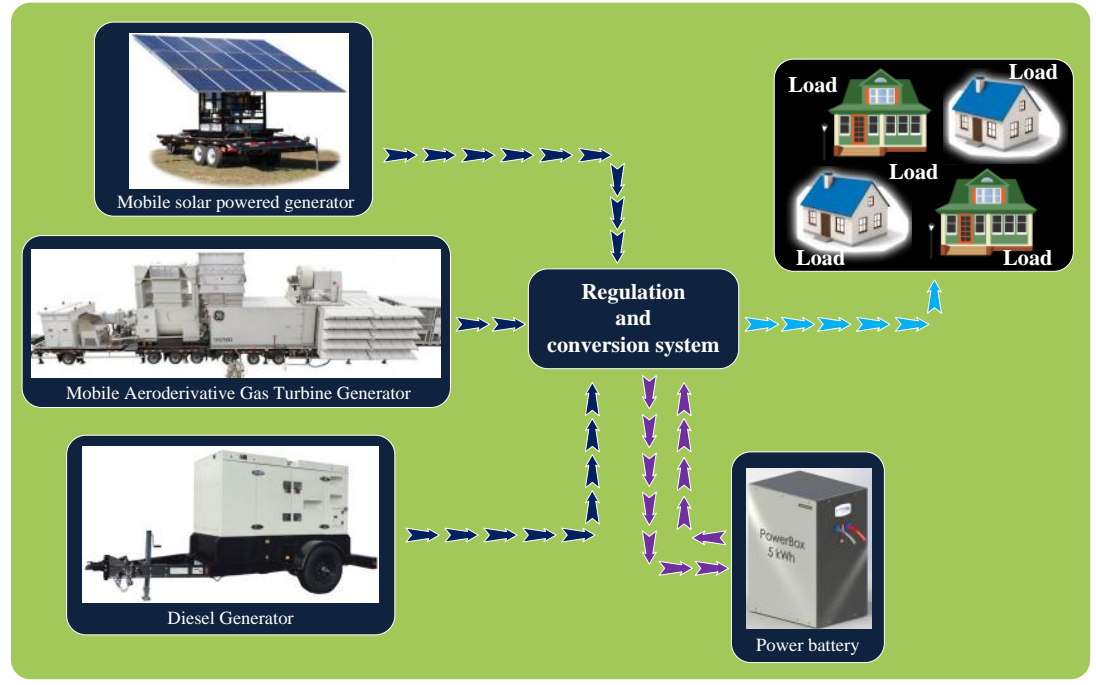

Fig. 1. Autonomous power supply system composition. 
Autonomous power supply technology is widely known such a concept as an autonomous or decentralized consumer's power supply system. In this case, a stand-alone power system (SAPS or SPS), also known as remote area power supply (RAPS) [5, 6], or, in other words, Autonomous Electric Energy Systems [7] or Autonomous Energy Grid [8] are used. This technology is an operation an off-the-grid electricity system for locations that are not fitted with an electricity distribution system.

Also, since the autonomous system usually has small dimensions, it is also called as microgeneration or microgrid [9]. Recently, special popularity and intensive development have Intelligent Distributed Autonomous Power systems (IDAPS), what is the improved version of SAPS. Typical autonomous system includes one or more methods of electricity generation from one or different sources, energy storage and regulation system $[2,6,7]$. Principal composition of typical autonomous power supply system is shown at figure 1 .

\subsection{Mobile and portable technology for power supply}

Using a mobile technology is one of the relatively new trends in disaster relief. It means to set power systems on trailers, or as a separate mobile element. For example it can be solar generator cart on wheels [2] or portable Power Station or Solar suitcase [2]. Then, this compact power sources move the energy supply to wherever it is needed and redeploy as necessary.

Mobile power systems are standalone systems which have been deployed to provide electricity to power radio stations, health clinics, shelters and homes at the disaster sites before utility electricity is restored. These systems should be assembled in a short time and able to replace general electric supply for specific consumers and life-support systems in many small applications.

Due to the impossibility of using photovoltaic (PV) power systems to eliminate the consequences of natural disasters at the Sakhalin region, the possibilities of using mobile sources on hydrocarbon fuel were considered.

An autonomous fuel power plant is a design that combines an engine with a current generator. All fuel power plants are divided into three types, depending on the operating fuel type: diesel, petrol or gas. Gasoline generators are most often used as backup power systems, designed for a short period of work. Gasoline-powered grids are compact, inexpensive and easy to use, but the high fuel consumption and high cost make such generators unprofitable under conditions of prolonged heavy use.

A diesel-electric power plant is more suitable for using in life-support systems, data centers, on construction area, etc. It may include one or more diesel-generator sets. Such power supply systems are more expensive than gasoline ones, they are more complicated constructively, however, they have lower fuel and maintenance costs. Diesel-generator sets consume $20-30 \%$ less fuel than gasoline ones, and their reliability indicators are higher. In addition, they are available in a wide power range, including low-power diapason.

Gas generators are usually used for the installation of autonomous power supply systems for large infrastructure facilities, industrial enterprises. They significantly differ in high cost and large dimensions. They have many advantages over other types of autonomous power plants. The main plus of gas generators is the low cost of energy. In addition, gas generators have a longer service life compared to other types of power plants, they are also easier to maintain and environmentally friendly. Aeroderivative type of gas turbine generator set can operate on gas and/or distillate liquid fuel, which allows using it in critical conditions of natural and technogenic disasters. According to many experts opinion, mobile power systems are battle proven and deliberately built for extreme conditions. This power solution as ideal for remote locations and unforgiving environments. 


\subsection{Gas power generation trends}

Now gas is the fastest growing of the fossil fuels and, within the next 10-15 years, is forecasted to become the single largest source of installed capacity, as it shown at figure 2 . By 2040, the OECD/IEA expects gas power to emerge as a player in the global energy mix, rivaling the popularity of the industry's traditional choices: coal and oil [1].

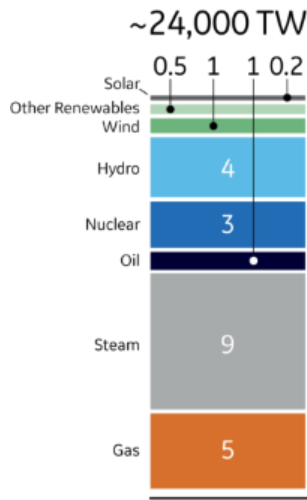

Generation 2015

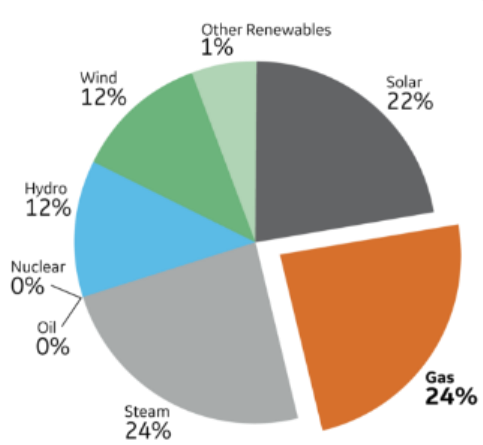

Capacity Additions

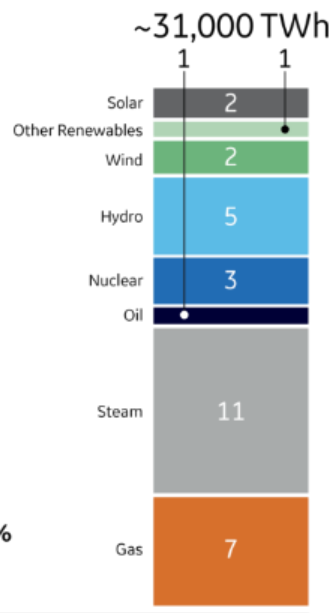

Generation 2025

Fig. 2. Power generation trends.

Renewable power capacity additions will be twice that of gas additions in the next decade; however larger load factors will allow gas and other fossil fuels to maintain their dominance in power generation. Gas turbine power plants serve as a complement to intermittent renewables generation, offering such valuable features as rapid start, output flexibility, and turndown capability. It is important that gas turbine technologies allow the creation of a mobile energy complex for development of all necessary types of energy. The use of gas turbine units, operating both on traditional and alternative fuels (wastes of thermoplastic polymers, ethanol, methanol, dimethyl ether, etc.) makes it possible to ensure acceptable environmental performance.

The using of biogas obtained from renewable raw materials by processing methods fermentation of domestic waste, poultry and livestock waste, sewage allows to significantly reduce the use of fossil organic fuels and carbon dioxide emissions. To meet the current fuel consumption standards efficiency is possible due to the complication of gas turbine cycles, by using binary, contact, cogeneration technologies [8]. In addition, in the context of eliminating the consequences of disasters, the use of biogas, taking into account the energy shortage, has a significant advantage over other types of power sources. The issues discussed are extremely important and require increased attention during the specialist's education and training in the electric power industry.

\section{Discussions}

The Calbuco volcano eruption in Chile in 2015, the Great East Japan earthquake in Japan in 2011 and other disasters have changed for last 10 years the attitude of the world community to the autonomous power supply technologies [1].

The importance of mobile and portable technology for power supply is recognized throughout the world and has given a powerful impetus to the development of mobile 
response technologies in the event of natural and man-made disasters. At the time of the Great East Japan earthquake a 'silent' revolution has been happening in Japan in the wake of the 2011 fatal earthquake and tsunami, with more and more municipalities setting up distributed energy systems to reduce reliance on the main grid, and secure electricity supply during natural disasters. There was also a sharp jump in the development of micro grids and decentralized installations for the production of renewable energy sources to reduce the dependence of electricity supply from the central network.

Modern autonomous distributed energy systems usually use small-scale power generation fueled by natural gas and/or solar and wind arrays and they use the internet to connect appliances and meters to better direct electric power depending on the needs. The world community is gradually moving towards the abandonment of large-scale power plants, which in the event of incidents fail, often leaving vital supplies without power supply. Instead, there is a steady trend of distributed power systems, where small power systems are located next to the consumption zones. In a number of cases for special territories and regions, due to the complexity in use solar and wind power plants after natural and technogenic disasters, using the gas turbine technologies has good prospects of mobile and portable technology for power supply at injured areas.

\section{Conclusions}

Obtained results leads to the following conclusions:

1. The safety requirements for power grid facilities in the event of a threat of a power failure and / or malfunction, clearly indicates the range of electricity consumers who need to ensure uninterrupted power supply.

2. Typical autonomous system includes one or more methods of electricity generation from one or different sources, energy storage and regulation system to improve the efficiency and reliability of its operation.

3. In conditions of a deficit of solar radiation, the first positions are taken by technologies using liquid fuel. Mobile power systems as aeroderivative type of gas turbine generator set can successful operate in critical conditions of natural and technogenic disasters and other extreme conditions.

4. It is very important, that autonomous energy supply technologies should be widely integrated into in engineering education, government and national programs, related to alternative energy and management of emergencies and emergencies.

\section{References}

1. S. Qazi, Standalone Photovoltaic (PV) Systems for Disaster Relief and Remote Areas (2017)

2. S. Makasheva, P. Pinchukov, MATEC Web of Conf. 86, 05025 (2016)

3. S. Makasheva, Russ. Electr. Engin. 87, 107 (2016)

4. J.R.E. Fletcher, T. Fernando, H.H.C. Iu, M. Reynolds, Sh. Fani, 2017 ISGT-Asia: IEEE Innov.Smart Grid Techn. - Asia (2017)

5. N. Mendis, K. M, Muttaqi, S, Perera, M, N. Uddin, IEEE Ind. Appl. Mag. 21(2) (2015)

6. J.A. Taylor, S.V. Dhople, D.S. Callaway, Renewable \& Sustainable Energy Reviews 57, 1322-1336 (2016)

7. B. Kroposki, E. Dall'Anese, A. Bernstein, Y. Zhang, B.-M. Hodge, Autonomous Energy Grids, Proc. of the 51st Hawaii Int. Conf. on System Sciences (2018)

8. E. Unamuno, J.A. Barrena, Development and Integration of Microgrids (2017) 